\title{
Ege Üniversitesi hastanesinde prostat kanserlerinin epidemiyolojisi ve genel sağkalım özellikleri
}

\section{Epidemiological and overall survival characteristics of prostate cancer in Ege} University hospital database

\begin{tabular}{|c|c|c|c|}
\hline Ayfer Haydaroğlu ${ }^{1}$ (iD) & Banu Sarsık Kumbaracı ${ }^{2}$ (D) & Deniz Yalman ${ }^{1}$ (iD & Serdar Özkök ${ }^{1}$ (D) \\
\hline İbrahim Cüreklibatır ${ }^{3}$ (D) & Oktay Nazlı ${ }^{3}$ (D) & Bülent Semerci ${ }^{3}$ (D) & Erdal Apaydın ${ }^{3}$ (D) \\
\hline Barış Altay ${ }^{3}$ (iD & Burak Turna $^{3}$ iD & Adnan Şimşir ${ }^{3}$ (D) & Erhan Gökmen ${ }^{4}$ (D) \\
\hline Jlus Şanlı $1^{4,5}$ (iD) & Bülent Karabulut ${ }^{4}$ iD & Sait Şen ${ }^{2}$ (D) & Sert $^{1}$ (D) \\
\hline mür ${ }^{6}$ iD & Fuat Kızılay ${ }^{3}$ iD & Serdar Kalemci ${ }^{3}$ (D) & \\
\hline \multicolumn{4}{|c|}{$\begin{array}{l}{ }^{1} \text { Ege Üniversitesi Tıp Fakültesi, Radyasyon Onkolojisi Anabilim Dalı, İzmir, Türkiye } \\
2 \text { Ege Üniversitesi Tıp Fakültesi, Tıbbi Patoloji Anabilim Dalı, İzmir, Türkiye } \\
{ }^{3} \text { Ege Üniversitesi Tıp Fakültesi, Üroloji Anabilim Dalı, İzmir, Türkiye } \\
{ }^{4} \text { Ege Üniversitesi Tıp Fakültesi, Medikal Onkoloji Bilim Dalı, İzmir, Türkiye } \\
{ }^{5} \text { Ege Üniversitesi Tıp Fakültesi, Kanserle Savaş Araştırma ve Uygulama Merkezi, İzmir, Türkiye } \\
{ }^{6} \text { Ege Üniversitesi Tıp Fakültesi, Nükleer Tıp Anabilim Dalı, İzmir, Türkive }\end{array}$} \\
\hline
\end{tabular}

\section{Öz}

Amaç: Ege Üniversitesi (EÜ) Hastanesinde 1992-2017 arası kanser tanı ve tedavisi yapılan prostat kanseri (PK) tanılı 4792 hastanın epidemiyolojik özellikleri, tedavi modaliteleri ve sağkalım özelliklerinin tanımlanması amaçlanmıştır.

Gereç ve Yöntem: EÜ Kanserle Savaş Araştırma ve Uygulama Merkezi tarafından toplanan PK verileri CANREG özel bilgisayar programına kaydedilmiş, DSÖ (Dünya Sağlık Örgütü) ve SEER (Surveillance, Epidemiolgy, and End Results) sistemleri temelinde gruplanarak analizler yapılmıştır. İstatistiksel analizlerde Kikare, General Linear Model, Kaplan Meier sağkalım analizleri uygulanmıştır. Kaplan-Meier Sağkalım analizinde Log Rank(Mantel-Cox), Breslow(Generalized Wilcoxon) ve TaroneWare istatistikleri kullanılmıştır. İstatistiksel analizlerde $p<0,05$ değeri anlamlı kabul edilmiştir.

Bulgular: PK tanılı 4792 hasta verisi analiz edilmiştir. Olgularımızda PK'ne en çok 60-69 yaş grubunda rastlanmaktadır. Histopatolojik olarak en sık "asiner adenokarsinom" görülmektedir. Evrelendirme çalışması yapılabilen PK'lerinde lokalize dönemin \%61,2 oran ile en fazla olduğu saptanmıştır. PK'lerinin görülüşünde yıllara göre doğrusal bir artış dikkat çekmektedir. Mortalitede ise 2008'e kadar doğrusal artış daha sonra azalış vardır. PK olgularımızda ortanca genel sağkalım(GSK) 120 aydır, tüm olgular için 5 ve 10 yıllık GSK'lar \%74,2 ve \%55,2 bulunmuştur.5 yıllık GSK oranları lokalize, lokal ileri ve metastatik evrelerde sırasıyla \%86,3, \%78,1 ve \%21,7 saptanırken 10 yıllık GSK için sırasıyla \%70, \%62,7 ve \%14'dür. Lokal ve lokal ileri evrelerde tedavi alanlarda sağkalımlarda anlamlı bir fark elde edilirken metastatik evrede anlamlı sonuç kaybolmaktadır.

Sonuç: EÜ Hastanesi Kanser veri tabanında bulunan 4792 PK'li bu seri tek merkez olarak Türkiye'deki en geniş PK serisidir. PK olgularımızda 5 ve 10 yıllık GSK oranları sırasıyla \%74,2 ve $\% 55,2$ bulunmuştur. Evrelere göre tedavilerin GSK'lar üzerine katkıları lokal ve lokal ileri evrede anlamlı bulunurken metastatik evrede bu anlamlılık kalmamaktadır.

Anahtar Sözcükler: Prostat Kanseri, Epidemiyoloji, Mortalite, Sağkalım.

Sorumlu yazar: Fatma Sert

Ege Üniversitesi Tıp Fakültesi, Radyasyon Onkolojisi

Anabilim Dalı, İzmir, Türkiye

E-posta: gracilis81@gmail.com 


\begin{abstract}
Aim: The aim of this study is to evaluate the epidemiological, treatment modality and survival characteristics of 4792 patients with Prostate Cancer $(P C)$ who were treated at Ege University Hospital (EUH).

Materials and Methods: The data were recorded using the CANREG programme. WHO (World Health Organization) and SEER (Surveillance, Epidemiolgy, and End Results) system were considered for classification and survival analysis. Chi-square test, General Linear Model and KaplanMeier survival analysis were done. Log Rank (Mantel-Cox), Breslow (Generalized Wilcoxon) and Tarone-Ware models were used for Kaplan-Meier survival analyses. $p$ value $<0.05$ was considered significant.
\end{abstract}

Results: Data of 4792 PC patients were analysed. PC was mostly seen in the age group of 60-69 years. Most common histological type was "acinary adenocarcinoma". Localized disease was most common (61,2\%) among patients who could be staged. There is a linear increase in prostate cancer according to years. There is a linear increase in mortality until 2008, then decrease afterwards. Median survival was 120 months. Five and 10-year overall survival (OS) rates were $74.2 \%$ and $55.2 \%$ respectively. Five-year OS rates for localized, locally advanced and metastatic disease were $86.3 \%$, $78.1 \%$ and $21.7 \%$ respectively whereas 10 -year OS rates were $70 \%, 62.7 \%$ and $14 \%$ respectively. Survival rates differ significantly in patients who were treated for localized and locally advanced disease while the difference disappeared for metastatic disease.

Conclusions: This is the largest prostate cancer data of a single center in Turkey with 4792 cases registered at EUH Cancer Database. Five and 10 year-OS rates were $74.2 \%$ and $55.2 \%$ respectively. Survival rates differ significantly in patients who were treated for localized and locally advanced disease while the difference disappeared for metastatic disease.

Keywords: Prostate cancer, epidemiology, incidence, mortality, survival.

\section{Giriş}

Erkeklerde en sık görülen kanser türü bazı ülkelerde akciğer, bazılarında ise prostat kanseridir. Kuzey ve Güney Amerika'daki tüm ülkeler, Avustralya, Avrupa'nın birçok ülkesi ve Afrika'nın bir bölümü dahil olmak üzere 87 ülkede prostat kanseri (PK) en sık görülen kanserdir. Akciğer kanseri ise Rusya, Çin, Doğu Avrupa ve Kuzey Afrika'nın bir bölümünde ve Türkiye dahil 38 ülkede erkeklerde en sık görülen kanserdir (1). GLOBOCAN 2018 verilerine göre tüm dünyada erkeklerde kanser insidansında sıklık açısından sıralamada akciğer kanserinden sonra PK ikinci sırada görülmektedir. PK'lerinde mortalite oranı düşük olup, akciğer, karaciğer, mide, kolorektal kanserlerin arkasından 5. sırada yer almaktadır (2). Amerika Birleşik Devletleri'nde dünya ortalamasından farklı bir görünüm vardır. Insidansda PK birinci sıradayken mortalitede akciğer kanserinin hemen ardından ikinci sıradadır (3). Avrupa'da PK insidansta birinci sırada, mortalitede ise akciğer ve kolorektal kanser arkasından 3. sırada bulunmuştur (4). Global istatistiklerde PK insidansında yıllara göre bir artış saptanırken mortalitede azalış olması dikkat çekicidir (5). Türkiye kanser verilerine göre
PK dünya ortalamasına benzer şekilde akciğer kanserinden sonra ikinci sırada görülmektedir (6).

$\mathrm{Bu}$ makalede Ege Üniversitesi Hastanesi'nde (EÜH) 1992-2017 yılları arasında PK tanısı ile tedavileri yapılan 4792 kayıtlı olgunun epidemiyolojik ve genel sağkalım (GSK) özellikleri istatistiksel açıdan değerlendirilmiş, sonuçlarımız literatürle karşılaştırılmıştır. İlgili Anabilim Dallarının müsaadesiyle etik onay alınarak yayınlanmaktadır.

\section{Gereç ve Yöntem}

Ege Üniversitesi Kanserle Savaş Araştırma ve Uygulama Merkezi tarafından toplanan PK verileri CANREG özel bilgisayar programına kayıt edilmiş, DSÖ (Dünya Sağlık Örgütü) ve SEER (Surveillance, Epidemiolgy, and End Results) sistemleri temelinde gruplanarak analizler yapılmıştır. İstatistiksel analizlerde Kikare, General Linear Model, Kaplan Meier sağkalım analizleri uygulanmıştır. Kaplan Meier Sağkalım analizinde Log Rank(Mantel-Cox), Breslow(Generalized Wilcoxon) ve Tarone-Ware istatistikleri kullanılmış. İstatistiksel analizlerde $p<0,05$ değeri anlamlı kabul edilmiştir. Sağkalım bilgileri nüfus bilgilerine ulaşılarak GSK olarak çıkarılmıştır. Ülkemizde 2000 yılından eski 
olgularda kimlik numarasına dayalı nüfus bilgilerine ulaşmak mümkün olmadığı için GSK nüfus bilgilerine ulaşılabilen yıllardaki olgular üzerinden çıkarılmıştır. Kanser kayıt sistemimizde veriler DSÖ'nün öngördüğü, T.C. Sağlık Bakanlığı'nın kabul ettiği şekilde toplanmış ve çalışmada veri sisteminde var olan kayıtlardan retrospektif olarak istatistik analizler yapılmıştır.

\section{Bulgular}

EÜ Hastane Tabanlı Kanser Kayıt sisteminde, 1992-2017 arası 25 yıl içinde kayıtlı olan, 4792 PK tanılı hasta verisi analiz edilmiştir. PK'lerinde yaşa, histolojiye, evrelere göre dağılımları, yıllara göre yeni tanı ve mortalite oranları, uygulanan tedavi özellikleri epidemiyolojik olarak irdelenmiş, bu veriler ışığında 5 ve 10 yıllık GSK oranları çıkarılmıştır.

\section{Epidemiyolojik Özellikler}

Olgularımızda prostat kanserinin en çok 60-69 yaş grubunda olduğu dikkati çekmektedir (Kikare $=5316,457 p<0,001$.). Prostat kanserlerinin yaş gruplarına göre dağılımı (Tablo-1 ve Şekil1)'de gösterilmiştir.

Tablo-1. Prostat kanserlerinin yaş gruplarına göre dağııımı.

\begin{tabular}{lll}
\hline Yaş Gurubu & Sayı & $\%$ \\
\hline $20-29$ & 3 &, 06 \\
$30-39$ & 4 &, 08 \\
$40-49$ & 107 & 2,23 \\
$50-59$ & 865 & 18,05 \\
$60-69$ & 2055 & 42,88 \\
$70+$ & 1758 & 36,69 \\
Toplam & 4792 & 100,00 \\
\hline
\end{tabular}

\section{Yaş Gurubuna Göre} Dağılım

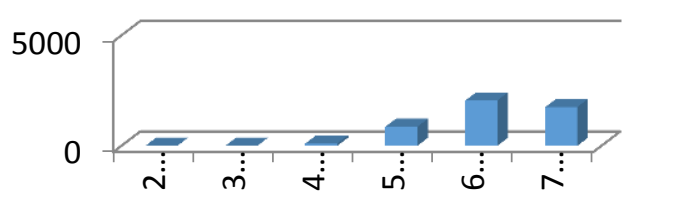

Şekil-1. Prostat kanserlerinin yaş gruplarına göre dağılımı.

Prostat dokusunda en sık epiteliyal tümör olan "asiner adenokarsinom" görülmektedir.
Serimizdeki 4661 olgu $(\% 97,3)$ pür asiner, 12 olgu pür duktal adenokarsinom olarak belirlendi. Asiner ve duktal adenokarsinom birlikteliği ise 17 olguda görüldü. Glandüler neoplazmların öncüsü olan "yüksek dereceli prostatik intraepitelyal neoplazi" 50 olguda saptandı (Tablo-2, Şekil-2).

Tablo-2. Prostat kanserleri patolojisi $(n=4792)$.

\begin{tabular}{lll}
\hline Histoloji & Sayı & $\%$ \\
\hline Asiner & 4661 & 97,3 \\
Asiner+Duktal & 17 &, 4 \\
Duktal & 12 &, 3 \\
PiN & 50 & 1,0 \\
Diğer & 52 & 1,1 \\
Toplam & 4792 & 100,0 \\
\hline
\end{tabular}

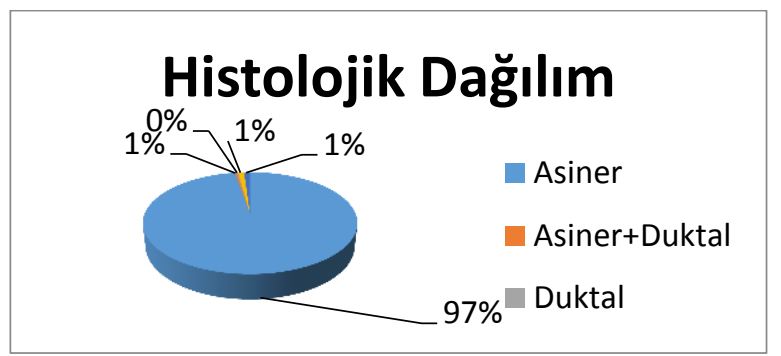

Şekil-2. Prostat kanserleri patolojisi $(n=4792)$.

Glandüler neoplaziler dışında yer alan tümörler "diğer" başlığı altında toplanmıştır. Bu grupta yer alan tümörler (Tablo-3)'te verilmiştir.

Tablo-3. Glandüler neoplaziler dışında yer alan diğer tümörler.

\begin{tabular}{lcc}
\hline Tümör tipi & N & $\%$ \\
\hline Indiferan karsinom & 8 & 15,39 \\
Lenfoma & 3 & 5,76 \\
Malign mezenkimal & 4 & 7,69 \\
Nöroendokrin karsinom & 8 & 15,38 \\
Skuamöz hücreli & 11 & 21,15 \\
karsinom & 18 & 34,63 \\
Ürotelyal karsinom & 52 & 100,00 \\
\hline Toplam & &
\end{tabular}

Olguların 2984'üne $\quad(\% 62,3) \quad$ evrelendirme yapılabilmiştir. Evrelendirme çalışması 
yapılabilen prostat kanserlerinde \%61,2'si lokalize, \%19,8'i lokal ileri, \%18,8'i metastatik dönemde tanı almaktadır (Tablo-4) (Şekil-3).

Tablo-4. Prostat kanserinde evrelere göre dağılım.

\begin{tabular}{lll}
\hline Evre & Sayı & $\%$ \\
\hline In situ & 66 & 2.2 \\
Lokal & 1825 & 61.2 \\
Lokal Ileri & 590 & 19.8 \\
Metastatik & 503 & 18.8 \\
Toplam & 2984 & 100 \\
\hline
\end{tabular}

\section{Evrelere Göre Dağılım}

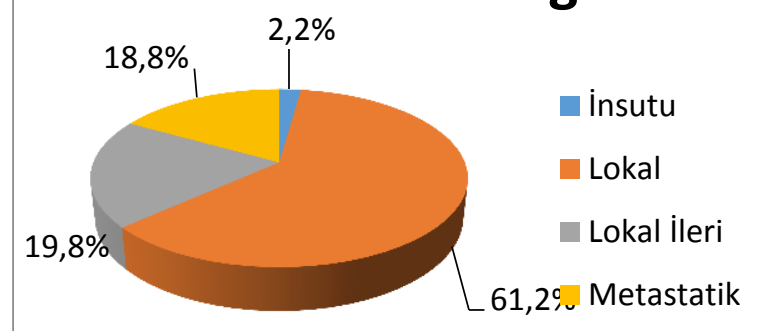

Şekil-3. Prostat kanserinde evrelere göre dağılım.

Prostat kanseri'nin görülüşünde yıllara göre doğrusal bir artış dikkat çekmektedir (GLM,F=10,686 $p<0,001$ ). Mortalitede ise 2008'e kadar doğrusal artış $(F=68,681 p<0,001)$ olduğu, daha sonra azalışa geçtiği izlenmektedir (Şekil4).

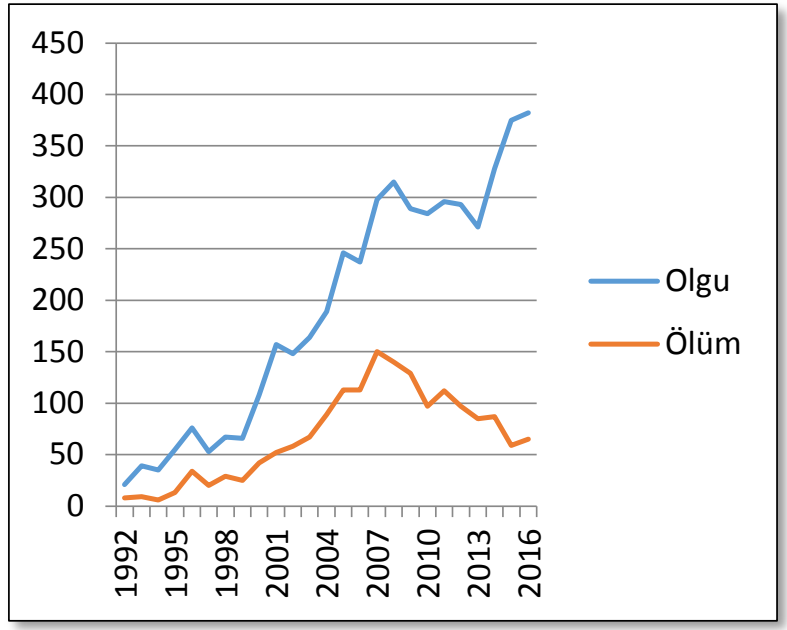

Şekil-4. Prostat kanseri yıllara göre artış eğilimi (n=4792).
Sağkalım:

Prostat kanserli olgularımızda sağkalım nüfus bilgilerine ulaşılabilen yıllardaki olgular üzerinden çıkarılmıştır. Ortanca sağkalım 120 ay, 5 yıllık GSK oranı \%74,2 ve 10 yıllık sağkalım oranı $\% 55,2$ 'dir (Tablo-5).

Tablo-5. Prostat kanserinde sağkalım oranları.

\begin{tabular}{|c|c|c|c|c|c|}
\hline Prostat & $n$ & $\begin{array}{l}\text { Ölüm } \\
\text { (n) }\end{array}$ & $\begin{array}{l}\text { Yaşayan } \\
\%\end{array}$ & $5 \mathrm{yll}$ & $\begin{array}{l}10 \\
\text { yIl }\end{array}$ \\
\hline & 3998 & 1503 & 62,3 & 74,2 & 55 \\
\hline
\end{tabular}

Prostat tümörlerinin yaş gruplarına göre 5 ve 10 yıllık GSK'ları ve sağkalım eğrileri (Tablo-6)'da ve (Şekil-5)'de gösterilmiştir.

Tablo-6. Prostat kanserlerinde yaş gruplarına göre sağkalım oranları.

\begin{tabular}{llllll}
\hline Yaş Grubu & $\mathbf{n}$ & $\begin{array}{l}\text { Ölüm } \\
\mathbf{n}\end{array}$ & $\begin{array}{l}\text { Yaşayan } \\
\%\end{array}$ & $\mathbf{5}$ yıl & $\mathbf{1 0} \mathbf{~ y ı l}$ \\
\hline $\mathbf{2 0 - 2 9}$ y & 2 & 1 & 50,0 & - & - \\
$\mathbf{3 0 - 3 9}$ y & 3 & 1 & 67,0 & - & - \\
$\mathbf{4 0 - 4 9}$ y & 94 & 14 & 77,7 & 83,3 & 62,7 \\
$\mathbf{5 0 - 5 9}$ y & 765 & 115 & 76,6 & 83,9 & 69,7 \\
$\mathbf{6 0 - 6 9}$ y & 1758 & 351 & 69,9 & 80,1 & 65,1 \\
$\mathbf{7 0}$ y üzeri & 1365 & 530 & 43,6 & 60,9 & 35,5 \\
\hline
\end{tabular}

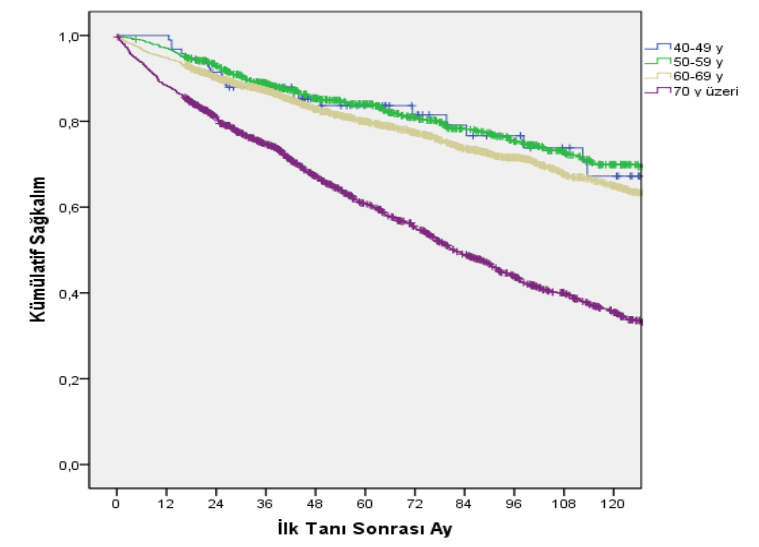

Şekil-5. Prostat kanserlerinde yaş gruplarına göre sağkalım eğrileri. 
En sık rastlanan histolojik tanı olan asiner kanserler için için 5 yıllık sağkalım $\% 74,8$ ve 10 yıllık sağkalım \% 57,3 ile iyi bir prognoz göstermektedir (Tablo-7) (Şekil-6).

Tablo-7. Histolojik tiplere göre sağkalım oranları

\begin{tabular}{|c|c|c|c|c|c|}
\hline \multirow{2}{*}{ Histoloji } & \multirow[b]{2}{*}{$\mathbf{N}$} & \multicolumn{2}{|c|}{ Yaşayan } & \multirow{2}{*}{$\begin{array}{l}5 \text { yıl } \\
\%\end{array}$} & \multirow{2}{*}{$\begin{array}{l}10 \text { yıl } \\
\%\end{array}$} \\
\hline & & $\mathbf{N}$ & $\%$ & & \\
\hline Asiner & 3912 & 2385 & 61,0 & 74,8 & 57,3 \\
\hline $\begin{array}{l}\text { Asiner+D } \\
\text { uktal }\end{array}$ & 16 & 9 & 56,3 & 66,5 & 47,5 \\
\hline Duktal & 12 & 8 & 66,7 & 69,4 & - \\
\hline PIN & 50 & 32 & 64,0 & 76,1 & 58,8 \\
\hline Diğer & 31 & 10 & 32,3 & 37,7 & 33,9 \\
\hline
\end{tabular}

Wilcoxon (Gehan) Statistic $=25,306 p<0,001$

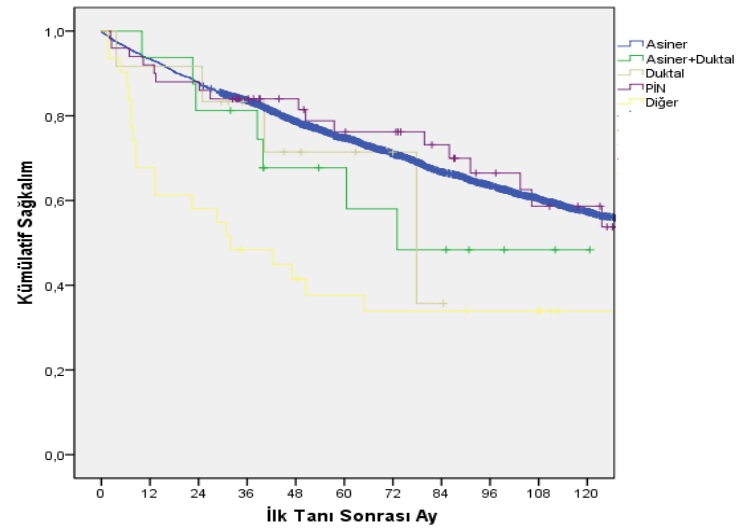

Şekil 6. Histolojik tiplere göre sağkalım grafiği.

Lokalize tümör evresinde tanı alan hastaların \%79,6'sı yaşarken, metastatik evrede "de novo" tanı alan hastaların \%23,3'ünün yaşadığı saptanmıştır. Beş ve 10 yıllık sağkalım oranları lokalize tümör ve lokal ileri evrede beklendiği gibi daha iyidir (Tablo-8 ve Şekil-7).

Tablo-8. Prostat kanserlerinde evrelere göre sağkalım oranları

\begin{tabular}{llllll}
\hline Evre & $\mathbf{n}$ & $\begin{array}{l}\text { Ölüm } \\
(\mathbf{n})\end{array}$ & $\begin{array}{l}\text { Yaşayan } \\
(\%)\end{array}$ & $\mathbf{5}$ yıl & $\mathbf{1 0} \mathbf{y ı l}$ \\
\hline In situ & 64 & 19 & 70,3 & $\mathbf{7 5 , 1}$ & $\mathbf{6 4 , 0}$ \\
$\begin{array}{l}\text { Lokalize evre } \\
\text { Lokal ileri }\end{array}$ & 1724 & 352 & 79,6 & $\mathbf{8 6 , 3}$ & $\mathbf{7 0 , 0}$ \\
$\begin{array}{l}\text { evre } \\
\text { Metastatik } \\
\text { evre }\end{array}$ & 487 & 148 & 69,6 & $\mathbf{7 8 , 1}$ & $\mathbf{6 2 , 7}$ \\
\hline
\end{tabular}

Tedavi:

Olgu kayıtlarında 3987 olguda tedavi uygulandığı bilgisine ulaşılmıştır. Geriye kalan olgular tedaviyi kabul etmeyenler, tedavisiz en iyi destek tedavi ile takibe alınanlar ve medikal nedenlerle tedaviye girmeyenlerdir. Olguların 2547'sine $(\% 63,9)$ cerrahi tedavi, 501'ine hormonoterapi $(\% 12,6), 605$ 'ine $(\% 15,2)$ radyoterapi ve 334 'üne $(\% 8,4)$ kemoterapi uygulanmıştır. Tedavi alan olgularımızda bekleneceği gibi sağkalımlar anlamlı bir şekilde daha iyi bulunmuştur (Tablo-9 ve Şekil-8).

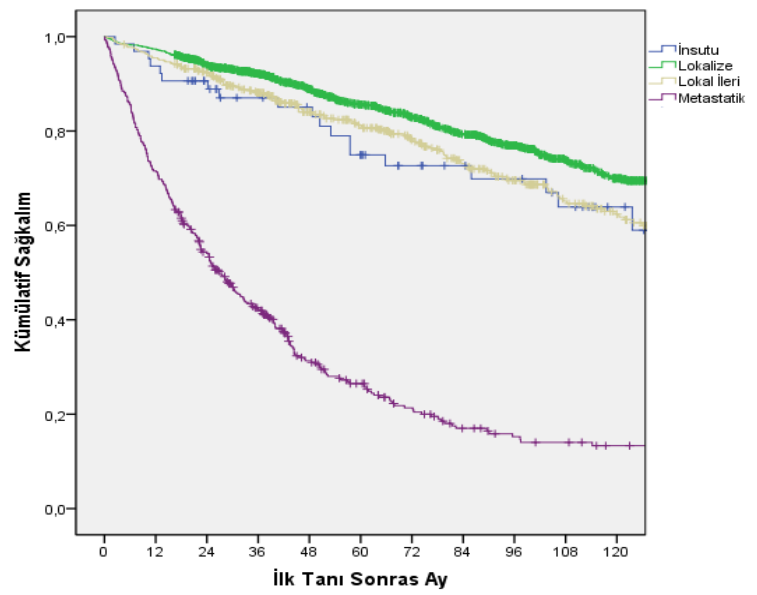

Şekil-7. Prostat kanserlerinde evrelere göre sağkalım grafiği.

Tablo-9. Tedavi alan ve almayan PK'li olgularımızda 5 ve 10 yıllık sağkalım oranları.

\begin{tabular}{|c|c|c|c|c|c|}
\hline \multirow{2}{*}{ Tedavi } & \multirow[b]{2}{*}{$\mathbf{N}$} & \multicolumn{2}{|c|}{ Yaşayan } & \multirow{2}{*}{$\begin{array}{l}5 \text { yıl } \\
\%\end{array}$} & \multirow{2}{*}{$\begin{array}{l}10 \text { yıl } \\
\%\end{array}$} \\
\hline & & $\mathbf{N}$ & $\%$ & & \\
\hline $\begin{array}{l}\text { Tedavi } \\
\text { Almayan }\end{array}$ & 1214 & 626 & 51,6 & 67,9 & 46,8 \\
\hline Tedavi Alan & 2807 & 1818 & 64,8 & 77,3 & 61,7 \\
\hline
\end{tabular}

Wilcoxon (Gehan) Statistic $=56,030 p<0,001$. 


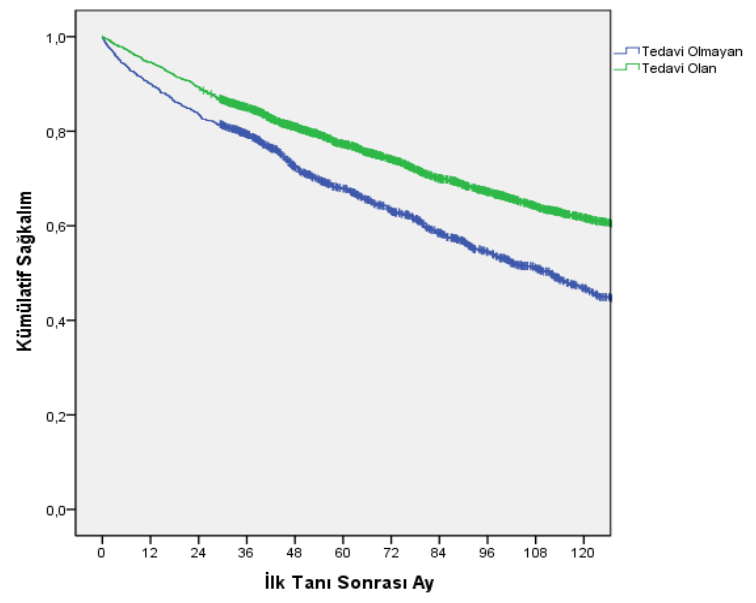

Şekil-8. Tedavi alan ve almayan prostat kanserli olgularımızda sağkalım eğrileri.

Tedavilere ve evrelere göre GSK'ları incelediğimizde tedavilerin sağkalıma katkıları evrelere göre değişim göstermektedir. Lokal evrede (Wilcoxon (Gehan) Statistic=92.492 $\mathrm{p}<0,001)$ ve lokal ileri evrede (Wilcoxon (Gehan) Statistic $=68,860 \quad p<0,001)$ istatistiksel olarak anlamlıyken metastatik evrede tedaviler sağkalıma katkıda bulunmamakta ve yararları palyasyon seviyesinde kalmaktadır (Wilcoxon (Gehan) Statistic=5,911 $p=0,206$ ). Lokal evrede hiç tedavi almayan hastalarda 5 yıllık sağkalım oranı \%74,8 iken bu oran cerrahi uygulananlarda $\% 91$ 'e çıkmaktadır. Yalnız radyoterapi uygulananlarda ise $\% 80$ civarıdır.

\section{Tartışma}

Tüm dünya genelinde erkeklerde sıklık açısından akciğer kanserinden sonra ikinci sıklıkta görülen prostat kanseri Amerika Birleşik Devletleri'nde ve Avrupa'da birinci sırada görülmektedir (2). Jemal ve arkadaşlarının global kanser insidans ve mortalite çalışmasında prostat kanseri insidansda ikinci, mortalitede altıncı sırada bulunmuştur (1). Siegel'in ABD'deki çalışmasına göre ise prostat kanseri \%19 ile birinci sıradayken mortalitede ikinci sıradadır (3). Avrupa ülkelerindeki kanser insidansı ve mortalitesi çalışmasında Avrupa'da erkeklerde en sık görülen kanser prostat kanseridir (4).

Türkiye kanser verilerinde yaşa göre standardize edilmiş hızı en fazla olan kanser türü akciğer kanseri $(\% 59,3)$ olup bunu ikinci sırada prostat kanseri $(\% 36,4)$ izlemektedir (6). Tüm yaş grupları dahil edildiğinde de sıralamada sonuç değişmemekte, dünya ortalamasına uyum göstermektedir. Bizim serimizde de prostat kanseri insidans sıralamasında akciğer kanserinden sonra 2. sıradadır.

Prostat kanseri tüm dünyada mortalite açısından akciğer, karaciğer, mide, kolorektal kanserler arkasından 5. sırada yer almaktadır (2). Amerika Birleşik Devletleri'nde ise mortalitede akciğer kanserinin hemen ardından ikinci sıradayken (3), Avrupa çalışmasında akciğer ve kolorektal kanserlerin ardından üçüncü sırada bulunmuştur. Bizim olgularımızda ise mortalite açısından prostat kanseri akciğer, hematopoetik sistem kanserleri ardından 3. sırada gelmektedir (4).

Global istatistiklerde yıllara göre prostat kanserinin insidansında doğrusal bir artış, mortalitede ise azalış vardır $(5,7)$. Bunun nedeni tıbbi teknolojilerdeki gelişime paralel olarak uygulanan radikal prostatektomi, radyoterapi gibi lokal tedavilerle ilişkili olduğu kadar moleküler biyoloji ve immunolojideki gelişmelerle hormonoterapi, kemoterapi vb sistemik tedavilerle de yakın bağlantılıdır. Avustralya ve Yeni Zelenda'da yaşa standardize mortalite oranı sırasıyla \%12,9 ve \%12,8 iken Türkiye'de \%22,8 olduğu rapor edilmiştir (8). Bizim serimizde ise prostat kanserlerinin görülüşünde yıllara göre doğrusal bir artış, mortalitede ise 2008'e kadar insidansa paralel doğrusal artış olduğu halde daha sonra literatürle uyumlu olarak azalışa geçtiği dikkati çekmektedir.

Düşük riskli ve erken evre prostat kanserlerinde tedavisiz aktif izlem seçeneği giderek yaygınlaşmaktadır. Bu konuda en geniş seri SEER verilerinden yararlanarak rapor eden Jeong ve arkadaşlarına aittir. Lokal evre (T12NOM0) prostat kanserli 257060 olgu tedavisiz aktif izlem ile takip edilmiş, sağkalım sonuçları araştırılmış, dikkatli gözlemin göz ardı edilemeyecek bir yöntem olduğunu rapor etmişlerdir (9). Lokalize prostat kanserinde aktif izlem seçeneği düşük riskli uygun prostat kanserinde gereksiz fazla tedavileri önlemektedir. Aktif izlem yaklaşımının prostat kanserine özgü sağkalım açısından \%97-100 arasında başarı oranına sahip olduğu görülmektedir (10). Farklı merkezlerde aktif izlem sonucu GSK'lar Royal Marsden'de \%98 (11), Miami Üniversitesinde \%100 (12), Johns Hopkins'de \%98 (13), Toronto Üniversitesinde \%68'dir (14).

Ülkemizdeki ortalama yaş sınırı Avrupa ve Amerika ortalamasına göre düşük olması, farklı nedenlerle olan ölümlerin genel sağkalım oranını etkilemesi nedeniyle doğal yollardan ölüm oranı arttığı için serimizde GSK'lar kaynaklara göre 
biraz daha düşük bulunmuştur. Serimizde hiç tedavi almayan tüm olgularda 5 yıllık genel sağkalım \%67,9 iken, tedavi almayan lokal evrelerde \%74,8'dir. Bizim serimizde lokal ve lokal ileri evrelerde tedaviler sağkalıma olumlu katkıda bulunurken metastatik evrede tedaviler sağkalıma anlamlı bir katkıda bulunmamıştır.

Knipper ve arkadaşları SEER verilerine göre kansere spesifik mortalite (KSM) oranlarını ( $n=579,369)$ yaşa, etnik kökene, evreye göre epidemiyolojik olarak değerlendirmişler ve 10 yıllık KSM oranlarını yayınlamışlardır (15). Yetmiş beş yaş üzeri olgularda KSM oranı \%14,6'dır. Bizim olgularımızda genel sağkalım oranları çıkarılmış ve ileri yaşta ölüm oranı daha yüksek bulunmuştur. Doğal nedenlere bağlı ölümlerin fazla olmasının bu durumu etkilediği düşünülmektedir. Yaşa göre 5 ve 10 yıllık GSK oranlarımız sırasıyla 50-59 yaş gurubunda $\% 83,9$ ve $\% 69,7$ iken, 70 yaş üzerinde $\% 60,9$ ve $\% 35,5$ 'dir.

\section{Sonuç}

EÜ Hastanesi Kanser veri tabanında bulunan 4792 prostat kanserli bu seri tek merkez olarak Türkiye'deki en geniş prostat kanseri serisidir.
Serimizde PK en sık 60-69 yaş grubunda görülmekte, ilk başvuru sırasında \%61,2'i lokalize, \%19,8'i lokal ileri, \%18,8'i metastatik dönemde tanı almaktadır. Prostat kanserlerinin görülüşünde yıllara göre doğrusal bir artış vardır. Beş ve 10 yıllık GSK oranları sırasıyla \%74,2 ve $\% 55,2$ 'dir. Beş ve 10 yıllık sağkalım oranları lokalize evrede $\% 86,3$ ve $\% 70$, lokal ileri evrelerde $\% 78,1$ ve $\% 62,7$, metastatik evrede ise $\% 21,7$ ve \%14'dür. Evrelere göre tedavilerin sağkalımlar üzerine katkıları lokal ve lokal ileri evrede anlamlı bulunurken metastatik evrede bu anlamlıık kaybolmakta, katkı palyasyon ile sınırı kalmaktadır.

Teşekkür: 25 yıllık süre içinde hasta alımında emekleri geçen Üroloji AD öğretim üyeleri Prof. Orhan Yurtseven, Prof. Dr. Atalay Gürsan, Prof. Dr. Necmettin Çıkılı, Prof. Dr. Gürhan Günaydın, Prof. Dr. Çağ Çal hocalarımıza, istatistik analizleri yapan EUKAM bilgisayar ve istatistik uzmanı Ömer Karaca'ya, EÜKAM kanser kayıt elemanlarına teşekkürü borç biliriz.

Çıkar çatışması: Yazarlar çıkar çatışması beyan etmemişlerdir.

\section{Kaynaklar}

1. Jemal A, Vineis P, Bray F, Torre L, Forman D (Editörler). Kanser Atlası. İkinci Baskı. Atlanta, GA: Amerikan Kanser Derneği; 2014. www.cancer.org/canceratlas

2. Bray F, Ferlay J, Soerjomataram I, Siegel RL, Torre LA, Jemal A. Global cancer statistics 2018: GLOBOCAN estimates of incidence and mortality worldwide for 36 cancers in 185 countries. CA Cancer J Clin 2018;68(6):394-424.

3. Siegel RL, Miller KD, Jemal A. Cancer Statistics, 2018. CA Cancer J Clin 2018;68(1):7-30.

4. Ferlay J, Colombet M, Soerjomataram I et al. Cancer incidence and mortality patterns in Europe: Estimates for 40 countries and 25 major cancers in 2018. Eur J Cancer 2018;103:356-87.

5. Center MM, Jemal $A$, Lortet-Tieulent $J$ et al. International variation in prostate cancer incidence and mortality rates. Eur Urol 2012;61(6):1079-92.

6. Gültekin M, Boztaş G. Türkiye Kanser İstatistikleri. TC Sağlık Bakanlığı, Türkiye Halk Sağlığı Kurumu, Kanser Savaş Daire Başkanlığı. 2016.

7. Wong MC, Goggins WB, Wang HH et al. Global incidence and mortality for prostate cancer: analysis of temporal patterns and trends in 36 countries. Eur Urol 2016;70(5):862-74.

8. Kimura T, Egawa S. Epidemiology of prostate cancer in Asian countries. Int J Urol 2018;25(6):524-31.

9. Jeong CW, Washington SL 3rd, Herlemann A, Gomez SL, Carroll PR, Cooperberg MR. The new Surveillance, Epidemiology, and End Results prostate with watchful waiting database: Opportunities and limitations. Eur Urol 2020;21. pii: S0302-2838(20)30045-2.

10. Tınay I, Türkeri L. Lokalize prostat kanserinde aktif izlem seçeneği. Üroonkoloji Bülteni 2012;11(2): 114-18.

11. van As NJ, Norman AR, Thomas $\mathrm{K}$ et al. Predicting the probability of deferred radical treatment for localised prostate cancer managed by active surveillance. Eur Urol 2008;54(6): 1297-305.

12. Soloway MS, Soloway CT, Eldefrawy A, Acosta K, Kava B, Manoharan M. Careful selection and close monitoring of low-risk prostate cancer patients on active surveillance minimizes the need for treatment. Eur Urol 2010;58(6):831-35. 
13. Tosoian JJ, Trock BJ, Landis $P$ et al. Active surveillance program for prostate cancer: An update of the Johns Hopkins experience. J Clin Oncol 2011; 29(16):2185-90.

14. Klotz L, Zhang L, Lam A ve ark. Clinical results of long-term follow-up of a large, active surveillance cohort with localized prostate cancer. J Clin Oncol 2010; 28: 126-131

15. Knipper S, Pecoraro A, Palumbo, C et al: The effect of age on cancer-specific mortality in patients with prostate cancer: a population-based study across all stages. Cancer Causes Control 2020;31(3):283-90. 